\title{
Ameliorative Effects of Fenugreek Seeds and Curcumin on Hematotoxicity induced by Nicotine in Male Albino Rats
}

\author{
Azab Elsayed Azab ${ }^{1 *}$, Mohamed Omar Albasha ${ }^{2}$ and Manal Abuelkasem Elnaif ${ }^{3}$ \\ ${ }^{1}$ Department of Physiology, Faculty of Medicine, Sabratha University, Libya. \\ ${ }^{2}$ Zoology Department, Faculty of Science, Alejalat, Zawia University, Libya. \\ ${ }^{3}$ Zoology Department, Faculty of Science, Zawia University, Libya.
}

Corresponding author: Azab Elsayed Azab, Department of Physiology, Faculty of Medicine, Sabratha, University, Libya.

Received date: October 22, 2021; Accepted date: November 18, 2021; Published date: January 03, 2022

Citation: Azab Elsayed Azab, Mohamed Omar Albasha and Manal Abuelkasem Elnaif. (2022) Ameliorative Effects of Fenugreek Seeds and Curcumin on Hematotoxicity induced by Nicotine in Male Albino Rats. J, Biotechnology and Bioprocessing 3(1); DOI: $10.31579 / 2766-2314 / 062$

Copyright: (C) 2022, Azab Elsayed Azab, This is an open access article distributed under the Creative Commons Attribution License, which permits unrestricted use, distribution, and reproduction in any medium, provided the original work is properly cited.

\begin{abstract}
The present study aimed to investigate the ameliorative effects of fenugreek seeds and curcumin on hematotoxicity induced by nicotine in male albino rats. 30 male F-344/NHsd Fischer rats, weighing from 180 to $200 \mathrm{~g}$ were used in the present study. The animals were divided into five groups (6 rats for each); Group I (control group), Group II (nicotine treated group), Group III (nicotine/fenugreek seeds co-administered), Group IV (nicotine/curcumin co-administered), and Group V (nicotine/curcumin\& fenugreek seeds co-administered). At the end of the experimentation and 24 hours after the last dose, all animals were anaesthetized with ether and blood samples were collected by heart puncture. The samples were collected in clean dry tubes containing the anticoagulant substance EDTA and used for the hematological studies. The results showed that the animals treated with nicotine for 4 weeks showed a significant decrease in RBCs count, hemoglobin concentration, hematocrit value, MCH, $\mathrm{MCHC}$, and platelets count, and increased MCV and WBCs count as compared to the control group. Co-administration of nicotine with fenugreek and/or curcumin caused improvement in all hematological parameters when compared with nicotine group. It can be concluded that nicotine had a strong effect on the hematological parameters. The ingestion of fenugreek and/or curcumin prevent the hematoxicity induced by nicotine. The current study suggests that fenugreek and curcumin may be useful in combating free radical-induced hematotoxicity induced by nicotine.
\end{abstract}

Keywords: nicotine, hematotoxicity, fenugreek, curcumin, co-administration, male albino rats

\section{Introduction}

Cigarette smoking and the use of other tobacco products became an important cause of increased mortality and morbidity in developed countries [1], because it increases the risk of heart disease, diabetes, lung cancer, respiratory disorders, and other illnesses [2].

Nicotine is one of hundreds of substances contained in cigarette smoke [1]. It is a highly toxic organic compound containing nitrogen and alkaloid which is mostly found in tobacco, [3] and responsible for its addiction [4].

Nicotine induces a production of free radicals and consequently oxidative stress [5]. People who smoke and also who are exposed to cigarette smoke indirectly by breathing the air in the same environment are exposed to nicotine induced oxidative stress $[6,7]$. Oxidative stress would result in increased free radical injury in the tissue leading to extensive tissue damage with subsequent derangement of cell physiology [1]. As a consequence, these radicals interact with cell components such as lipids, proteins, DNA, RNA, carbohydrates and enzymes [7, 8]. So, that smoking has an effect on the various metabolic and biological processes in the body [1]. Nicotine can easily pass through the cell membrane and react to tubulin protein present in the cytoplasm of multiplying cells and cause cell division disorder [9]. It increases the risk of coronary artery disease [10] and promotes tumor growth as well as atherosclerosis formation [11]. Also, nicotine consumption can decrease fertility drive in males through inducing oxidative stress and DNA damage [12].

The body is engaged in a constant battle against damaging chemicals called free radicals or pro-oxidants to counter the harmful effects of free radicals, the body manufactures antioxidants to chemically neutralize them. However, the natural antioxidant system may not always be equal to the task. Sources of free radicals, such as cigarette smoke may overwhelm this defense mechanism [13].

Natural antioxidants strengthen the endogenous antioxidants defenses and restore the optimal balance by neutralizing reactive species [14]. Curcumin as one of the naturally occurring dietary substances has been 
used since ancient times for promoting human health [15]. Curcumin is a major yellow pigments in rhizomes of Curcuma longa which is used widely as a spice and coloring agent in several foods [16]. It represents a class of anti-inflammatory and anti-oxidant reported to be a potent inhibitor of reactive oxygen species formation [17].

Fenugreek (Trigonella foenumgraecum) is an annual herb belonging to Legume family; it is widely grown in India, Egypt, and Middle Eastern countries [18]. It used both in medicine and with food as spice show antioxidant effect through their used in diabetes mellitus due to the presence of different active constituents such as flavonoids, alkaloids, vitamins and amino acids [19]. The yellowish seeds contain compounds with interesting proprieties which explain their use in various ways including medicine, nutrition, beverages, fragrances, cosmetics, smoking and for other industrial purposes [20]. In fact, toasted and ground fenugreek seed is an essential ingredient of curry powders and is often mixed with breadstuffs [21].

Plant seeds and herbs are used for treatments of diseases in the folk medicine. Their use was increased in many fields due to their safetyness and its low side effects as compared with chemical drugs [22]. Antioxidant potential of curcumin and fenugreek seeds in the amelioration of nicotine induced oxidative stress need thorough investigation because these natural antioxidants are components of many edible substances and has the potential for safe future use by humans. The evidence reporting the protective effect of curcumin and fenugreek seeds against nicotine induced hematotoxicity are hardly found.

\section{Objectives}

The present study aimed to evaluate the protective effects of fenugreek seeds, and curcumin on hematotoxicity induced by nicotine in male albino rats.

\section{Materials and Methods}

\subsection{Experimental Animal}

Animals were used in this study were 30 male F-344/NHsd Fischer rats, weighing from 180 to $200 \mathrm{~g}$. Animals were purchased from Animal Welfare House of Libyan National Medical Research Centre, Zawia, Libya. Rats were kept under standard veterinary hygienic conditions for cleanliness and health care and normal conditions through the whole experimental periods. Rats were separated in plastic cages, 6 rats per cage, and left one week of acclimation, before commencing the experiment. The rats were kept in a room under standard conditions of ventilation, temperature $\left(25 \pm 4^{\circ} \mathrm{C}\right)$, humidity $(65 \pm 5 \%)$ with light/dark cycle. A standard rodent pellet consisting of a mixture of protein, fat, fiber, and ash were used to feed the rats. Food and water were supplied ad-libitum.

\subsection{Methods and Technique}

\subsubsection{The drug}

Nicotine hydrogen tartrate salt (1-methyl-2-(3-pyridyl) pyrrolidinebitartrate salt) was purchase from Sigma-Aldrich (St. Louis, MO, USA). Nicotine is a colorless organic Liquid. It was dissolved in physiological saline ( $0.9 \%$ sodium chloride) and was injected subcutaneously daily with $0.8 \mathrm{mg}$, nicotine $/ \mathrm{kg}$ body weight for 30 days.

\subsubsection{Curcumin, and Fenugreek seeds}

Curcumin was given in diet as $20 \mathrm{~g} / \mathrm{kg}$ diet daily for 30 days. Fenugreek seeds were finely grounded and added to the experimental diets as 7.5 $\mathrm{g} / \mathrm{kg}$ diet daily for 30 days.

\subsection{Experimental Design}

After one week of acclimation, the animals were randomized and divided into five groups (6 male albino rats for each) as follow:
Group I (control group): This group included 6 animals that were injected subcutaneously with saline daily, provided with tape water and fed with normal diet for 30 days.

Group II (nicotine treated group): Male rats were injected subcutaneously daily with $0.8 \mathrm{mg}$, nicotine $/ \mathrm{kg}$ body weight for 30 days.

Group III (nicotine/fenugreek seeds co-administered): The animals were injected subcutaneously daily with $0.8 \mathrm{mg}$, nicotine $/ \mathrm{kg}$ body weight concurrently with fenugreek seeds $7.5 \mathrm{~g} / \mathrm{kg}$ diet daily for 30 days.

Group IV (nicotine/curcumin co-administered): The animals were injected subcutaneously daily with $0.8 \mathrm{mg}$, nicotine $/ \mathrm{kg}$ body weight concurrently with curcumin $20 \mathrm{~g} / \mathrm{kg}$ diet daily for 30 days.

Group V (nicotine/curcumin\& fenugreek seeds co-administered): The animals were injected subcutaneous daily with $0.8 \mathrm{mg}$, nicotine $/ \mathrm{kg}$ body weight concurrently with curcumin $20 \mathrm{~g} / \mathrm{kg}$ diet and fenugreek seeds 7.5 $\mathrm{g} / \mathrm{kg}$ diet daily for 30 days.

\subsection{Blood Sampling:}

At the end of the experimentation and 24 hours after the last dose, all animals were anaesthetized with ether and blood samples were collected by heart puncture. The samples were collected in a clean dry tube containing the anticoagulant substance EDTA (ethylene diamine tetra acetic acid) and used for the hematological studies.

\subsection{Determination of Haematological parameters:}

Red blood cells count, haemoglobin concentration, hematocrit value, mean corpuscular volume, mean corpuscular haemoglobin, mean corpuscular haemoglobin concentration, white blood cells count, differential count of leucocytes, and blood platelets count were determined using an automated haematology analyzer Sysmex (KX. 21) machine.

\subsection{Statistical Analysis: -}

Results were expressed as mean \pm standard deviation, Data were analyzed by one way ANOVA. The difference between means \pm SD was tested at $\mathrm{P}<0.05$ using Duncan's multiple range test. In all statistical tests, the probability level of $P<0.05$ was considered significant.

\section{Results}

4.1. Effect of administration of nicotine, and coadministration of nicotine with fenugreek seeds, nicotine with curcumin and nicotine, fenugreek seeds, and curcumin on haematological parameters in male rats.

Haematological parameters of the different groups are shown in table .1 and figures (1-8). Male rats that received intraperitoneal injection of nicotine only $(0.8 \mathrm{mg} / \mathrm{kg}$ body weight /day) for 30 consecutive days had significantly $(P<0.01)$, decreased RBCs count, hemoglobin concentration, hematocrit value, $\mathrm{MCH}, \mathrm{MCHC}$, and platelets count, and increased $\mathrm{MCV}$ and $\mathrm{WBCs}$ count as compared to the control group.

The results of the study showed that the male rats injected subcutaneous daily with $0.8 \mathrm{mg}$, nicotine/ $\mathrm{kg}$ body weight concurrently with fenugreek seeds $7.5 \mathrm{~g} / \mathrm{kg}$ diet daily for 30 consecutive days resulted in a significant $(P<0.01)$ decrease in RBCs count, $\mathrm{MCH}, \mathrm{MCHC}$, and platelets count, and at $(P<0.05)$ in hemoglobin concentration, and hematocrit value, and a significant $(P<0.01)$ increased in MCV and WBCs count as compared to the control group (Table.1\& Figures 1-8). Conversely, co-administration of fenugreek seeds with nicotine significantly $(P<0.01)$ improved all haematological parameters when compared with nicotine group Table. $1 \&$ Figures 1-8).

Co-administration of $0.8 \mathrm{mg}$, nicotine/ $\mathrm{kg}$ body weight subcutaneously with curcumin $20 \mathrm{~g} / \mathrm{kg}$ diet daily for 30 consecutive days caused a 
significant $(P<0.01)$ decrease in RBCs count, hemoglobin concentration, and hematocrit value, $\mathrm{MCH}, \mathrm{MCHC}$, and platelets count, and a significant $(P<0.01)$ increased in MCV and WBCs count as compared to the control group. Conversely, co-administration of curcumin with nicotine significantly $(P<0.01)$ improved all haematological parameters when compared with nicotine group (Table.1\& Figures 1-8).

The animals injected subcutaneous daily with $0.8 \mathrm{mg}$, nicotine $/ \mathrm{kg}$ body weight concurrently with curcumin $20 \mathrm{~g} / \mathrm{kg}$ diet and fenugreek seeds 7.5 $\mathrm{g} / \mathrm{kg}$ diet daily for 30 consecutive days were showed a significant $(P<0.01)$ decrease in $\mathrm{MCH}, \mathrm{MCHC}$, and platelets count, and a significant $(P<0.01)$ increased in MCV and WBCs count as compared to the control group (Table.1\& Figures 1-8). Conversely, co-administration of fenugreek and curcumin with nicotine significantly $(P<0.01)$ improved all haematological parameters when compared with nicotine group Table.1\& Figures 1-8).

\begin{tabular}{|c|c|c|c|c|c|}
\hline Groups & Control & Nicotine & $\begin{array}{l}\text { Nicotine+ } \\
\text { Fenugreek }\end{array}$ & $\begin{array}{l}\text { Nicotine+ } \\
\text { Curcumin }\end{array}$ & $\begin{array}{l}\text { Nicotine+ } \\
\text { Fenugreek+ } \\
\text { Curcumin }\end{array}$ \\
\hline Parameters & Mean \pm SD & Mean \pm SD & Mean \pm SD & Mean \pm SD & Mean \pm SD \\
\hline RBCs $\left(\times 10^{6} / / \mu \mathrm{L}\right)$ & $9.7 \pm 0.2$ & $7.7 \pm 0.4^{* *}$ & $8.9 \pm 0.1^{* * \# \#}$ & $8.6 \pm 0.1^{* * \# \#}$ & $9.3 \pm 0.1^{\# \#}$ \\
\hline Hb (g/dl) & $15.1 \pm 0.2$ & $11.9 \pm 0.9^{* * *}$ & $14.3 \pm 0.2^{* \# \#}$ & $13.9 \pm 0.2^{* * \# \#}$ & $14.8 \pm 0.1^{\# \#}$ \\
\hline HCT $(\%)$ & $54.2 \pm 1.2$ & $43.5 \pm 3.3^{* *}$ & $50.4 \pm 0.3^{* \# \#}$ & $48.2 \pm 0.7^{* * \# \#}$ & $51.5 \pm 0.7^{\# \#}$ \\
\hline $\operatorname{MCV}\left(\mu^{3}\right)$ & $52.5 \pm 1.5$ & $60.9 \pm 1.5^{* *}$ & $55.9 \pm 0.5^{* * \# \#}$ & $57.4 \pm 0.6^{* * \# \#}$ & $54.7 \pm 0.3^{* * \# \#}$ \\
\hline MCH (pg) & $17.0 \pm 0.4$ & $14.9 \pm 0.2^{* * *}$ & $15.8 \pm 0.1^{* * \# \#}$ & $15.3 \pm 0.2^{* * \# \#}$ & $16.2 \pm 0.1^{* * \# \#}$ \\
\hline MCHC (g/dl) & $30.6 \pm 0.8$ & $26.3 \pm 0.4^{* *}$ & $27.9 \pm 0.4^{* * \# \#}$ & $27.1 \pm 0.3^{* * \# \#}$ & $29.1 \pm 0.1^{* * \# \#}$ \\
\hline WBCs $\left(\times 10^{3} / / \mu \mathrm{L}\right)$ & $6.7 \pm 0.7$ & $14.4 \pm 1.2^{* * *}$ & $10.7 \pm 0.3^{* * \# \#}$ & $11.9 \pm 0.6^{* * \# \#}$ & $10.1 \pm 0.3^{* * \# \#}$ \\
\hline PLTs $\left(\times 10^{3} / / \mu \mathrm{L}\right)$ & $2021 \pm 54$ & $1282 \pm 155^{* *}$ & $1840 \pm 65^{* * \# \#}$ & $1605 \pm 83^{* * \# \#}$ & $1943 \pm 37^{* * \# \#}$ \\
\hline
\end{tabular}

*: Significant at $(\mathrm{P}<0.05)$ when compared with control group, **: Significant at $(P<0.01)$ when compared with control group, \#\#: Significant at $(P<0.01)$ when compared with nicotine group.

Table.1: Effect of administration of nicotine, and co-administration of nicotine with fenugreek seeds, nicotine with curcumin and nicotine with fenugreek seeds, and curcumin on haematological parameters in male rats.

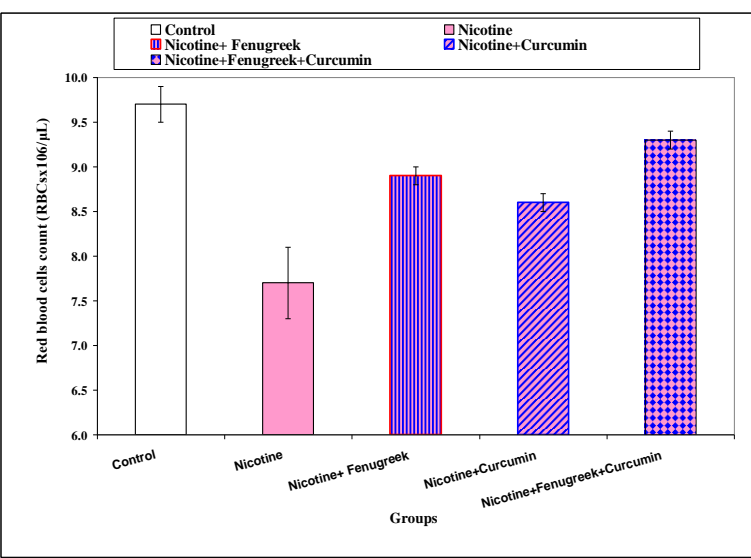

Figure.1: Effect of administration of nicotine, and coadministration of nicotine with fenugreek seeds, nicotine with curcumin and nicotine with fenugreek seeds, and curcumin on RBCs count in male rats.

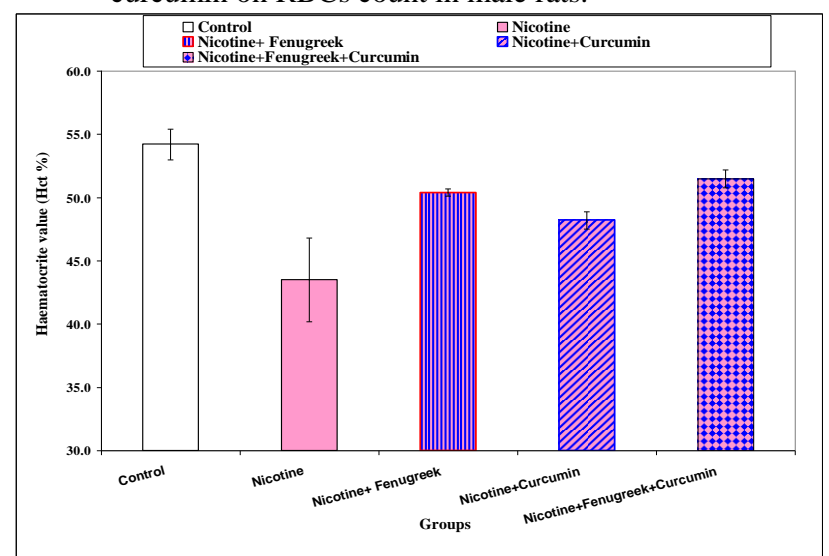

Figure.3: Effect of administration of nicotine, and coadministration of nicotine with fenugreek seeds, nicotine

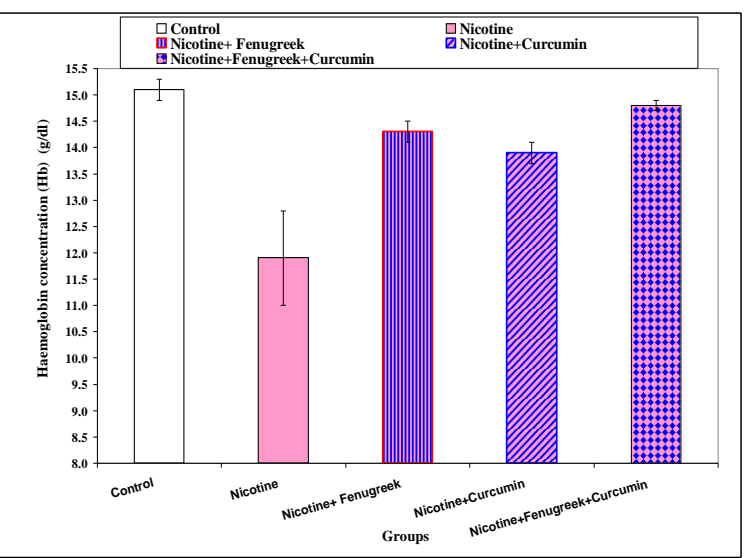

Figure.2: Effect of administration of nicotine, and coadministration of nicotine with fenugreek seeds, nicotine with curcumin and nicotine with fenugreek seeds, and curcumin on haemoglobin concentration in male rats.

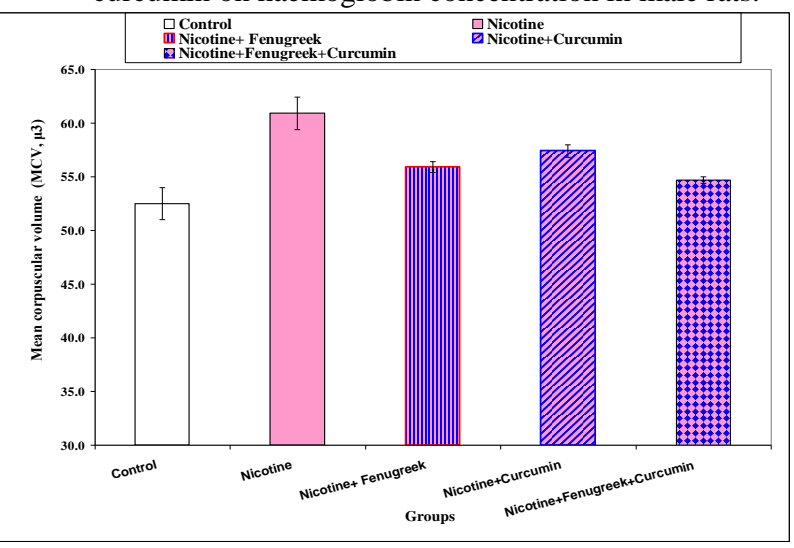

Figure.4: Effect of administration of nicotine, and coadministration of nicotine with fenugreek seeds, nicotine with 
with curcumin and nicotine with fenugreek seeds, and curcumin on hematocrit value (Hct) in male rats.

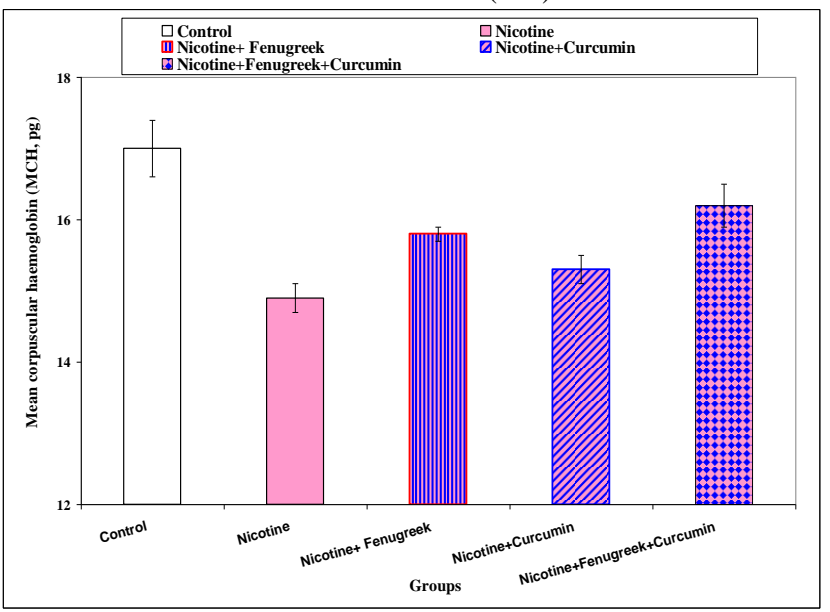

Figure.5: Effect of administration of nicotine, and coadministration of nicotine with fenugreek seeds, nicotine with curcumin and nicotine with fenugreek seeds, and curcumin on mean corpuscular haemoglobin $(\mathrm{MCH})$ in male rats.

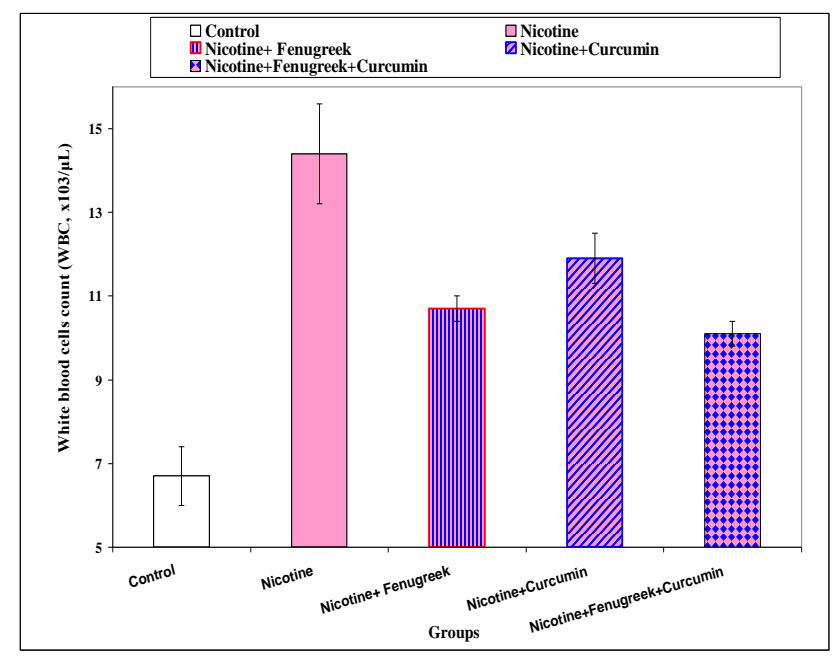

Figure.7: Effect of administration of nicotine, and coadministration of nicotine with fenugreek seeds, nicotine with curcumin and nicotine with fenugreek seeds, and curcumin on WBCs count in male rats.

\section{Discussion}

In the current study, male rats that received intraperitoneal injection of nicotine only $(0.8 \mathrm{mg} / \mathrm{kg}$ body weight /day) for 30 consecutive days had significantly $(\mathrm{P}<0.01)$, decreased $\mathrm{RBCs}$ count, hemoglobin concentration, hematocrit value, $\mathrm{MCH}, \mathrm{MCHC}$, and platelets count, and increased $\mathrm{MCV}$ and WBCs count as compared to the control group. These results are similar to the study of Sharif et al., [23] who reported that mice injected with $1 \mathrm{mg} / \mathrm{kg}$ body weight of nicotine daily for 6 weeks caused a significant $(\mathrm{p} \leq 0.05)$ increase in hematocrit, mean corpuscular volume, and white blood cells, and a significant decrease in RBCs count, mean corpuscular hemoglobin, hemoglobin, and mean corpuscular hemoglobin concentration compared with control group. Corre et al., [24] recorded that smoking caused a significant increase in WBCs count and a decrease in RBCs count. Also, nicotine causes many changes in blood cells as it curcumin and nicotine with fenugreek seeds, and curcumin on mean corpuscular volume (MCV) in male rats.

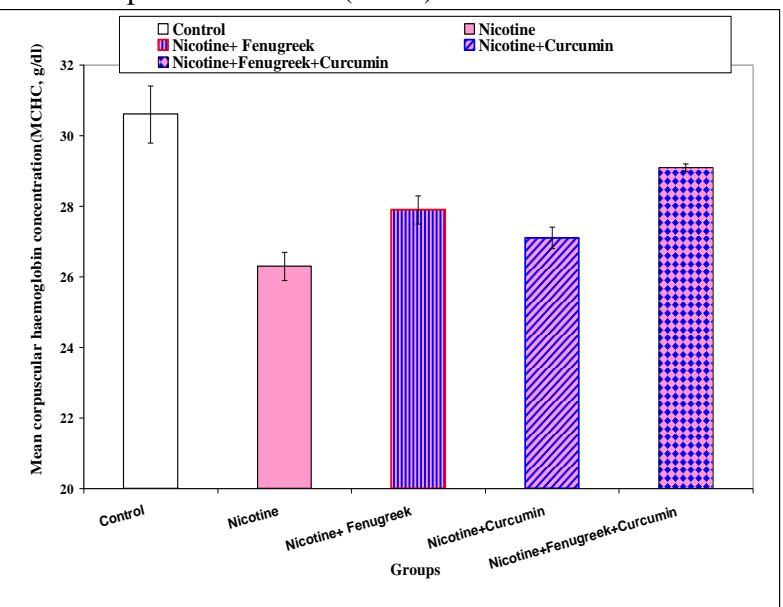

Figure.6: Effect of administration of nicotine, and coadministration of nicotine with fenugreek seeds, nicotine with curcumin and nicotine with fenugreek seeds, and curcumin on mean corpuscular haemoglobin concentration $(\mathrm{MCHC})$ in male rats.

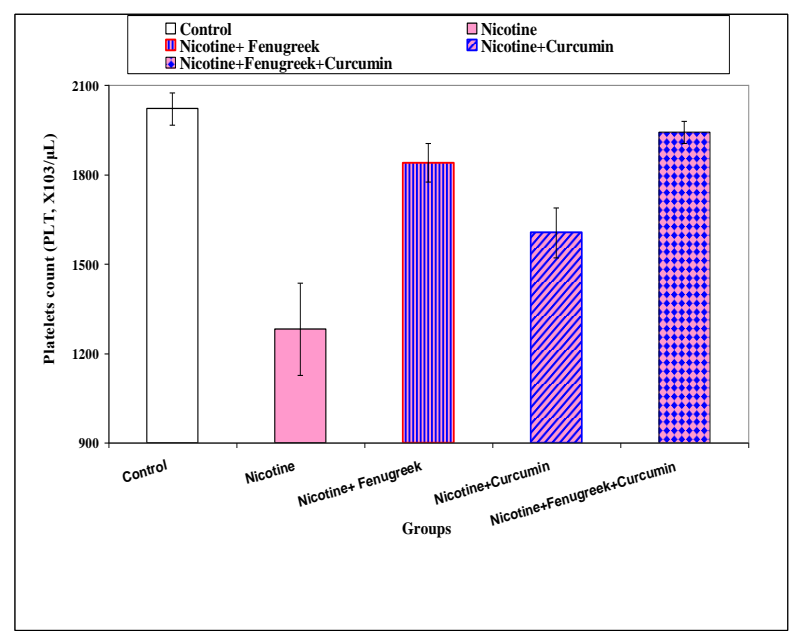

Figure.8: Effect of administration of nicotine, and coadministration of nicotine with fenugreek seeds, nicotine with curcumin and nicotine with fenugreek seeds, and curcumin on platelets count in male rats.

simply diffuses into the cells [25, 26]. Also, Zafar et al., [27] reported that cigarette smoking caused a significant $(\mathrm{p} \leq 0.05)$ decreased hemoglobin level. Okuno [28] reported that smoking caused a significant increase in MCV and a significant decrease in $\mathrm{MCH}$ and MCHC. The previous studies [23, 29, and 30] showed that nicotine administration caused a decrease in the proliferation of red blood cells and as a result, the RBCs count decreases. Low erythrocytes count may lead to a number of physiological disorders.[23] Nicotine greatly suppresses the function of the immune system and due to this reason the number of WBCs increased in the body to strengthen the immune system [23, 31].

Co-administration of fenugreek seeds with nicotine significantly $(\mathrm{P}<0.01)$ improved all haematological parameters, increase in RBCs count, $\mathrm{MCH}$, $\mathrm{MCHC}$, and platelets count, and at $(\mathrm{P}<0.05)$ in hemoglobin concentration, and hematocrit value, and a significant $(\mathrm{P}<0.01)$ decreased in $\mathrm{MCV}$ and 
WBCs count as compared to the nicotine treated group. These results run parallel to those reported by many previous studies [32-34]. The study of Rosioru et al.,[35] reported that treatment of rats with $10 \%$ ethanol in drinking water for 30 days caused a significant increase in RBCs count, Hct value, and $\mathrm{Hb}$ concentration, WBCs count, and lymphocytes percentage and a decrease in neutrophils percentage as compared to the control animals. Addition of $10 \%$ fenugreek flour in the diet of ethanolintoxicated rats for 30 days showed a tendency to restore the control values

Hamden et al., [36] reported that fenugreek oil was ameliorated the altered hematological parameters in diabetic rats through its antioxidant properties that may be due to their content of polyphenolic flavonoids [37, 38].

Also, Abdel-Daim et al., [39] recorded that rats treated with $15 \mathrm{mg} / \mathrm{kg}$ bw deltamethrin orally showed a significant decrease in RBCs and platelet counts, hemoglobin concentration, and hematocrit value and a significant increase in leucocytes count when compared with the control group. But, co-administration of rats with fenugreek oil contained diets $(2.5 \%$ and $5 \%$ ) and $15 \mathrm{mg} / \mathrm{kg}$ bw deltamethrin orally resulted in a significant increase in RBCs and platelets counts, hemoglobin concentration and hematocrit value and a significant decrease in leucocytes count as compared with deltamethrin treated rats. Fenugreek oil kept the studied hematological parameters within normal ranges. Thus, including fenugreek oil in the diets of deltamethrin administrated rats prevented the oxidative stress induced by deltamethrin, which subsequently protects the immune and hemopiotic organs.

Kandhare et al., [40] reported that fenugreek seeds influenced the hemoglobin and lymphocytes count, improving hematopoietic function.

Al-Amri and Alrasheedi,[41] demonstrated that feeding of rats on a diet supplemented with fenugreek seeds at a concentration of $5 \%$ before and after 14 days of irradiation exposure significantly increased hemoglobin and lymphocytes percentage compared to the control group. Also, it was demonstrated the role of fenugreek seeds in protecting the spleen and increasing lymphocytes, suggesting that fenugreek seeds might improve immunity.

Abdel-Rahman et al., [42] reported that lactating female rabbits treated with fenugreek germinated and powdered seeds showed a significant increase in RBCs count, $\mathrm{Hb}$ concentration $\mathrm{Hct}$, and $\mathrm{MCH}$ values. Administration of fenugreek-germinated seeds; oil or powdered seeds to lactating female rabbits were improved RBCs count, Hct, Hb, blood indices, and WBCs count.

Pradeep and Srinivasan, [43] reported that streptozotocin-induced diabetic rats caused a significant decrease in $\mathrm{RBCs}$ count, $\mathrm{Hb}$ concentration, MCV, Hct value, $\mathrm{MCH}, \mathrm{MCHC}$, and platelets count in diabetic rats. Hyperglycemia increases the production of free radicals and oxidative stress that in turn is a cause of cellular dysfunction. Dietary fenugreek seeds $(100 \mathrm{~g} / \mathrm{kg})$ and onion $(30 \mathrm{~g} / \mathrm{kg})$ treatment of streptozotocin-induced diabetic rats, appeared to counter the deformity of erythrocytes partially in diabetic rats by their antioxidant potential. Dietary fenugreek seeds and onion caused a decrease in glycated haemoglobin,[43] and a nephro-protective [44] probably mediated by stimulating erythropoietin which enhances rapid synthesis of RBCs as indicated by the improved level of $\mathrm{MCH}$ and $\mathrm{MCHC}$ in diabetes treated groups.

Elghazaly et al.,[45] reported that the combination treatment of rats with Glimepiride and a fenugreek aqueous extract in streptozotocin induced diabetic in male albino rats for eight weeks caused an improvement in $\mathrm{RBC}$ count, $\mathrm{Ht}$ value, $\mathrm{Hb}$ concentration, $\mathrm{MCHC}$ value, platelets count, and total WBCs count compared with the diabetic rats.
In addition, Algridi, and Azab, [34] recorded that treatment of male rabbits with aluminum chloride was decreased red blood cell count, hemoglobin concentration, haematocrite, mean corpuscular hemoglobin, mean corpuscular hemoglobin concentration, and mean corpuscular volume values, and a significant increase in WBCs count, differential count of leukocytes, and platelets count as compared with the control rabbits. Co-administration of fenugreek seeds powder to male rabbits with aluminum chloride resulted in a significant improvement in hematological parameters.

The improvement in hematological parameters caused by treatment with fenugreek may be due to the antioxidant activity of flavonoids present in fenugreek seeds, thereby elevating the antioxidant capacity of the blood, $[32,35,39,42,46]$ the antioxidant property of fenugreek inhibits lipid peroxidation of the erythrocytes, [47] and the high iron content of fenugreek seed flour stimulated hemoglobin synthesis. [42, 45] Also, fenugreek seeds extract showed protective effects against hydrogen peroxide-induced oxidation by protecting the erythrocytes from hemolysis and lipid peroxidation due to the presence of flavonoids and polyphenols [48]. Fenugreek seeds may be improving immunity because they play a role in protecting the spleen and increasing the lymphocytes. [40, 45, 49] Abdel-Rahman et al., [42] suggested that the administration of fenugreek powdered seeds were responsible for the improvement of immunological profile through increase phagocytic index, phagocytic capacity of macrophages, and humoral immunity.

Improvement in platelet count may be due to the inhibitory activity of certain constituents of fenugreek on platelet aggregation $[45,50]$.

The current study showed that co-administration of $0.8 \mathrm{mg}$, nicotine $/ \mathrm{kg}$ body weight subcutaneously with curcumin $20 \mathrm{~g} / \mathrm{kg}$ diet daily for 30 consecutive days caused a significant $(\mathrm{P}<0.01)$ decrease in $\mathrm{RBCs}$ count, hemoglobin concentration, and hematocrit value, $\mathrm{MCH}, \mathrm{MCHC}$, and platelets count, and a significant $(\mathrm{P}<0.01)$ increased in $\mathrm{MCV}$ and $\mathrm{WBCs}$ count as compared to the control group. Conversely, co-administration of curcumin with nicotine significantly $(\mathrm{P}<0.01)$ improved all haematological parameters when compared with nicotine group. These results run parallel to the results of Elsayed and Hegazi [51]. who reported that mice exposed to gasoline vapor 2hours/day for 3 weeks in inhalation chamber showed a reduction in bone marrow cellularity and slow rate of cells maturation. Apoptosis appeared in bone marrow cells by histopathological examination for biopsies. Also, reduction in a blood cell counts was occurred, in RBCs, WBCs, platelets, and hemoglobin. Lymphocytes percentages in blood were depressed and neutrophils percentages were elevated in gasoline inhalation group. All these were improved and returned to the normal levels by providing mice with curcumin in the diet. Curcumin protected leukocytes from depression caused by gasoline. This effect of curcumin on hematopoiesis may be due to its strong inhibiting effect on myeloperoxidase activity which is the cornerstone enzyme in benzene hematotoxicity [51]. The immune modulatory functions of curcumin had appeared in the study of Antony et al., [52] when WBCs count, circulatory antibody titer against sheep $\mathrm{RBCs}$, the plaque forming cells in the spleen, significantly increased with curcumin administration to Balb/c mice. Kato et al., [53] estimated that curcumin strongly inhibited myeloperoxidase activity in vitro. Pal et al., [54] recorded that curcumin administration to tumor-earing mice decreased tumor cell number significantly in a dose- dependent manner. Furthermore, tumor induced depletion of immune cell number of the host, as was evidenced from the decrease in bone marrow progenitor as well as thymic and splenic mononuclear cell numbers was reinitiated by curcumin. Moreover, rather in tumor-bearing mice it inhibited hematopoietic toxicity, and activated depressed antioxidant and detoxification systems. Deng et al., [55] concluded that, curcumin and its analogues are effective antioxidants which can protect human red blood cells from free radical- induced oxidative haemolysis and the $\mathrm{H}$-atom 
abstraction from the phenolic group is responsible for the activity. The observations of Deng et al., [55] that the compounds bearing orthodiphenoxyl functionality exhibit markedly higher anti-haemolysis activities than those bearing no such functionality gives us useful information for antioxidant drug design. Kempaiah and Srinivasan [56] demonstrated that curcumin has displayed a protective influence on the erythrocyte integrity in the high fat diet-induced hyperlipidemia.

The present study showed that the animals injected subcutaneous daily with $0.8 \mathrm{mg}$, nicotine $/ \mathrm{kg}$ body weight concurrently with curcumin $20 \mathrm{~g} / \mathrm{kg}$ diet and fenugreek seeds $7.5 \mathrm{~g} / \mathrm{kg}$ diet daily for 30 consecutive days were caused a significant improvement in all hematological parameters when compared with nicotine group. These parameters were nearly similar to that in the control groups that may be due to the additive antioxidant effect of fenugreek and curcumin together. Al Anany et al., [57] reported that combined therapy with both curcumin and quercetin was much better than each one alone. Because, previous studies reported that natural antioxidants strengthen the endogenous antioxidants defenses from reactive oxygen species and restore the optimal balance by neutralizing reactive species [58, 59]. Curcumin has anti-inflammatory and antioxidant properties with a potent ability to inhibit reactive oxygen species formation.[60] Curcumin represents a class of anti-inflammatory and antioxidant reported to be a potent inhibitor of reactive oxygen species formation.[17] Fenugreek had a different active constituents such as flavonoids, alkaloids, vitamins and amino acids.[19] The ameliorative effect of fenugreek and curcumin against nicotine induced hematotoxicity may be due to decrease nitric oxide production, uremic toxin, and increasing radical-scavenging enzyme activity through scavenging reactive oxygen and nitrogen species and chelating redex-active transition metal ions.

\section{Conclusion}

It can be concluded that nicotine had a strong effect on the hematological parameters. The ingestion of fenugreek and/or curcumin prevent the hematoxicity induced by nicotine. The current study suggests that fenugreek and curcumin may be useful in combating free radical-induced hematotoxicity induced by nicotine.

\section{References}

1. Abdel-Aziz, H. O. (2010) Morphological evaluation on the protective effect of Curcumin on Nicotine Induced Histological Changes of the Adrenal Cortex in Mice. Egypt. J. Histol. 33(3): 552 - 559.

2. Jessen, A.B., Toubro, S. Astrup, (2003) A. Effect of chewing gum containing nicotine and caffeine on energy expenditure and substrate utilization. Amer. J. Clin. Nutr. 77 ( 6 ): 14421447.

3. Jana, K.; Samanta, P. K., De, D. K. (2010) Nicotine diminishes testicular gametogenesis, steroidogenesis, and steroidogenic acute regulatory protein expression in adult albino rats: possible influence on pituitary gonadotropins and alteration of testicular antioxidant status. Toxicol. Sci., 116(2): 647- 659.

4. Benowitz N.L., Schultz K.E., Haller C.A., Wu A.H.B., Dains K.M., Jacob P. (2009) Prevalence of smoking assessed biochemically in an urban public hospital: A rationale for routine cotinine screening. Am. J. Epidemiol., 170(7): 885891.

5. Sanchez-Moreno, C., Larrauri, J. A., Saura- Calixto, F. (1999) Free radical scavenging capacity and inhibition of lipid oxidation of wines, grape juices and related polyphenolic constituents. Food Res Inter. 32(6): 407-412.

6. Suleyman H., Gumustekin K., Taysi S., Keles S., Oztasan N., Aktas O., et al. (2002) Beneficial effects of Hippophae rhamnoides L. on nicotine induced oxidative stress in rat blood compared with vitamin E. Biol. Pharm. Bull., 25(9): 11331136.

7. Ekinci, D., Senturk M., Beydmir S., Kufrevioglu O.I., Supuran C.T. (2010) An alternative purification method for human serum paraoxnase and its interactions with sulfonamides. Chem. Biol. Drug Design, 76(6): 552- 558.

8. Ekinci, D., Ceyhun S.B., Senturk M., Erdem D., Kufrevioglu O.I., Supuran C.T. (2011) Characterization and anions inhibition studies of an á-carbonic anhydrase from the teleost fish Dicentrarchus Iabrx. Bioorganic Med. Chem. Lett., 19(2): 744- 748.

9. Gorrod, J. W. (1993) The mammalian metabolism of nicotine: an overwiew. In: Gorrod, J. W. and Wahren, J. (Eds.). Nicotine and related alkaloids absorption, distribution, metabolism and excretion. London, Chapman and Hall. pp. 31-44.

10. Swislocki, A.L., Tsuzuki, A., Tait, M., Khuu, D., Fann, K. (1997) Smokeless nicotine administration is associated with hypertension but not with a deterioration in glucose tolerance in rats. Metabol. 46: 1008-1012.

11. Heeschen, C., Jang, J.J., Weis, M., Pathak, A., Kaji , S., Hu, R.S., et al. (2001) Nicotine stimulates angiogenesis and promotes tumor growth and atherosclerosis. Nat. Med., 7: 833839.

12. Jalili, C., Khani, F., Salahshoor, M. R., Roshankhah, S. (2014) Protective effect of curcumin against nicotine-induced damage on reproductive parameters in male mice. Int. J. Morphol. 32(3): 844-849.

13. EBSCO, CAM (on line). Review board: Conditions: Atherosclerosis and heart disease prevention, 2007, pp. 4.

14. Ho C., Ferrara T., Chen Q., Rosen R., Huang M. (2004) Phytochemicals in teas and rosemary and their cancer preventive properties in food phytochemicals for cancer prevention. Amer. Chem. Soci., Washington, 1994: 2-19.

15. Joe B., Vijaykumar M., Lokesh B.R. (2004) Biological properties of curcumin-cellular and molecular mechanisms of action. Crit. Rev. Food Sci. Nutr., 44: 97-111.

16. Tirkey N., Kaur G., Vij G., Chopra K. (2005) Curcumin a diferuloylmethane, attenuates cyclosporine induced renal dysfunction and oxidative stress in rat kidneys. J Biosc, 22(2): 233- 246.

17. Venkatesan N, Punithavathi D, and Arumugan V. (2000) Curcumin prevent adriamycin nephrotoxicity in rats. $\mathrm{Br} J$ Pharmacol, 12: 231-234.

18. Flammang A.M., Cifone M.A., Ereson G.L., Stankowskci L.F. (2004) Genotoxicity testing of fenugreek extract. J. Food Chem. Toxicol., 42: 205-208.

19. Basch E., Ulbricht C., Kuo G., Szapary P., Smith M. (2003) Therapeutic application of fenugreek. Altern. Med. Rev., 8(1): 20-27.

20. Djeridane, A., Yousfi, M., Nadjemi, B., Boutassouma, D., Stocker, P., Vidal, N. (2006) Antioxidant activity of some Algerian medicinal plants extracts containing phenolic compounds. Food Chem., 97: 654- 660.

21. Blank, I., Lin, J., Devaud, S., Fumeaux, R., Fay, L.B. (1997) The principal flavor components of fenugreek (Trigonella foenum-graceum L.). In Risch S. J. and Ho C.T. (Eds.), Spices: Flavor chemistry and antioxidant properties, Washington: American Chemical Society. ACS Symposium Series, 660: 12 - 28 .

22. Alhawari S. (1986) Medical plants as food and medicine. Suid. Ara. J., 21: 70 -71.

23. Sharif S., Farasat T., Fatima N., Farooq A., Naz S. (2014) Effect of nicotine on hematology, lipid profile and liver 
enzymes in adult male mice (Mus musculus). Adv. Anim. Vet. Sci., 2 (4): 222 - 225.

24. Corre F, Lellouch J, Schwartz D. (1971) Smoking and leukocyte counts. Results of an epidemiologic study. Lancet., 2: $632-634$.

25. Rausch JL, Fefferman M, Ladisich-Rogers DG, Menard M. (1989) Effect of nicotine on human blood platelet serotonin uptake and efflux. Progress in Prog. Neuropsychopharmacol. Biol. Psychiatry., 13: 907 - 916.

26. Schwartz K, Weizman A, Rehavi M. (2005) Decreased platelet vesicular monoamine transporter density in habitual smokers. European Neuro-psychopharmacol., 15: 235- 238.

27. Zafar I, Khan NM, Nisar M, Rashida M, Shumaila B, Syed AM. (2003) Effect of cigarette smoking on erythrocytes, leukocytes and hemoglobin. J. Med. Sci., 3(3): 245 - 250.

28. Okuno T. (1973) Smoking and blood changes. J. Med. Assoc., 225: 1387-1388.

29. Sherwin MA, Gastwirth CM. (1990) Detrimental effects of cigarette smoking on lower extremity wound healing. J. Foot Surg., 29: 84-87.

30. Siana JE, Frankild S, Gottrup F. (1992) The effect of smoking on tissue function. J. Wound Care, 1 (2): $37-41$.

31. Geng Y, Savage SM, Razan-Boroujerdi S, Sopori ML. (1996) Effects of nicotine on the immune response. Chronic nicotine treatment induces T cell energy. J. Immun., 156: 2384 - 2390.

32. Bravo L. (1998) Polyphenols, chemistry, dietary sources, metabolism and nutritional significances. Nutr Rev., 11: 317333.

33. Effraim KD, Salami HA, Nwafor PA. (1999) The Effect of aqueous seed extract of Trigonella foenum graecum (fenugreek) on hematological parameters in albino rats. African J Biomed Res., 2: 47-51.

34. Algridi MA., Azab AE. (2021) Ameliorating effects of fenugreek seeds powder against hematotoxicity induced by aluminum chloride in male rabbits. J. Biotechnol Bioproc., 2(4); 1-9, DOI: 10.31579/2766-2314/035

35. Rosioru C, Pribac G, Simeoni I, Craciun C, Ardelean A. (2010) Trigonella foenum graecum L (sickle fruit fenugreek) seed-anatural hepatoprotector that prevents ethanol-induced toxicity. Ann Romanian Soc Cell Biol., 15(2): 390-399.

36. Hamden, K., Keskes, H., Belhaj, S., Mnafgui, K., Feki, A., Allouche, N. (2011) Inhibitory potential of omega-3 fatty and fenugreek essential oil on key enzymes of carbohydratedigestion and hypertension in diabetes rats. Lipids Health Dis., 10(226): 1-10.

37. Kaviarasan, S., Anuradha, C. V. (2007) Fenugreek (Trigonella foenum graecum) seed polyphenols protect liver from alcohol toxicity: a role on hepatic detoxification system and apoptosis. Pharmazie., 62(4): 299-304.

38. Belaid-Nouira, Y., Bakhta, H., Haouas, Z., Flehi-Slim, I., Ben Cheikh, H. (2013) Fenugreek seeds reduce aluminum toxicity associated with renal failure in rats. Nutr Res Pract. 7(6): 466474.

39. Abdel-Daim, M.M., Abd Eldaim, M.A., Mahmoud, M.M. (2014) Trigonella foenum-graecum protection against deltamethrin-induced toxic effects on haematological, biochemical, and oxidative stress parameters in rats. Canadian J Physiol Pharmacol., 92(8): 679-685.

40. Kandhare AD, Bodhankar SL, Mohan V, Thakurdesai PA. (2015) Effect of glycosides based standardized fenugreek seed extract in bleomycin induced pulmonary fibrosis in rats: Decisive role of Bax, Nrf2, NF- B, Mucac, TNF- and IL-1. Chem. Biol. Interact., 237:151-165.
41. Al-Amri S, Alrasheedi A. (2016) Effect of fenugreek seeds on haematogenesis in irradiated rats. World Appl Sci J., 34(2): 147-157.

42. Abdel-Rahman, H., Fathalla, S. I., Assayed, M. E., Masoad, S. R., Nafeaa, A.A. (2016) Physiological Studies on the Effect of Fenugreek on Productive Performance of White NewZealand Rabbit Does. Food Nutr Sci., 7(13): 1276-1289.

43. Pradeep SR, Srinivasan K. (2018) Haemato-protective influence of dietary fenugreek (Trigonella foenum-graecum L.) seeds is potentiated by onion (Allium cepa L.) in streptozotocin-induced diabetic rats. Biomed Pharmacother. 98: 372-381.

44. Pradeep SR, Srinivasan K. (2018) Alleviation of oxidative stress-mediated nephropathy by dietary fenugreek (Trigonella foenum-graecum) seeds and onion (Allium cepa) in streptozotocin-induced diabetic rats. Food Funct. 9(1): 134148.

45. Elghazaly, N. A., Zaatout, H. H., Radwan, E. H., Elghazaly, M. M., Elsheikha, E. A. (2019) Trigonella foenum graecum extract benefits on hematological, biochemical and male reproductive system as a complementary therapy with Gimepiride in treating streptozotocin induced diabetic rats. $J$ Bioinform Diab., 1(3): 45-59.

46. Arivalagan, M., Gangopadhyay, K. K., Kumar, G. (2013) Determination of steroidal saponins and fixed oil content in fenugreek (Trigonella foenum-graecum) genotypes. Indian $J$ Pharm Sci, 75(1): 110-113.

47. Thirunavukkarasu V, Anuradha C, Viswanathan P. (2003) Protective effect of fenugreek (Trigonella Foenum graecum) seeds in experimental ethanol toxicity. Phytother Res., 17(7):737-743

48. Kaviarasan S, Vijayalakshmi K, Anuradha C. (2004) Polyphenol-rich extract of fenugreek seeds protects erythrocytes from oxidative damage. Plant Foods Hum Nutr. 59: 143-147.

49. Sindhu G, Ratheesh M, Shyni GL, Nambisan B, Helen A. (2012) Anti-inflammatory and antioxidative effects of mucilage of Trigonella foenum graecum (Fenugreek) on adjuvant induced arthritic rats. Int. Immunopharmacol., 12: 205-211.

50. Lawson SR, Gabra BH, Guerin B, Neugebauer W, Nantel F, Sirois P. (2005) Enhanced dermal and retinal vascular permeability in streptozotocin-induced type 1 diabetes in Wistar rats: blockade with an elective bradykinin B1 receptor antagonist. Regul. Pept. 124 (1-3): 221- 224.

51. Elsayed ASI, Hegazi MA. (2016) Ameliorative effects of curcumin and green tea against gasoline inhalation Hematotoxicity. Inter J Appl Biol Pharm Technol., 7(1): 1-18.

52. Antony, S., Kuttan, R. Kuttan, G. (1999) Immunomodulatory activity of curcumin. Immunol. Invest. 28(5-6): 291-303.

53. Kato, Y. Nagao, A. Terao, J., Osawa, T. (2003) Inhibition of myeloperoxidase-catalyzed tyrosylation byphenolic antioxidants in vitro. Biosci. Biotechnol. Biochem. 67(5): 1136-1139.

54. Pal, S., Bhattacharyya, S., Choudhuri, T. (2005) Amelioration of immune cell number depletion and potentiation of depressed detoxification system of tumor-bearing mice by curcumin. Cancer Detect Preven. 29: 470-478.

55. Deng, S.L., Chen, W.F., Zhou, B., Liu, Z.L. (2006) Protective effects of curcumin and its analogues against free radicalinduced oxidative hemolysis of human red blood cells. Food Chem. 98: 112-119. 
56. Kempaiah, R.K., Srinivasan, K. (2005) Influence of dietary spices on the fluidity of erythrocytes in hypercholesterolemic rats. Br. J. Nutr., 93: 81-91.

57. Al Anany MGE, Kamal AM, El Saied K. (2015) Effects of curcumin and/or quercetin on nicotine-induced lung and liver toxicity in adult male albino rat. Al-Azhar Assiut Med J., 13(2): 93-102.

58. Albasha M O, and Azab AE. (2014) Effect of cadmium on the liver and amelioration by aqueous extracts of fenugreek seeds, rosemary, and cinnamon in Guinea pigs: Histological and biochemical study. Cell Biol, 2(2): 34-44.
59. Fetouh FA, and Azab, AE. (2014) Ameliorating effects of curcumin and propolis against the reproductive toxicity of gentamicin in adult male Guinea pigs: Quantitative analysis and morphological study. Amer J Life Sci., 2(3): 138-149.

60. Biswas S.K., Mc Clure D., Jimenez L.A., Megson I.L., Rahman I. (2005) Curcumin induces glutathione biosynthesis and inhibit NF-kappa B activation and interleukin-8 release in alveolar epithelial cells. Mechanism of free radical scavenging activity. Anti. Red. Sign. 7: 32-41. 